L'HOMME L'Homme

Revue française d'anthropologie

$190 \mid 2009$

Varia

\title{
Corinne Cauvin Verner, Au désert
}

\section{François Pouillon}

\section{OpenEdition}

Journals

Édition électronique

URL : http://journals.openedition.org/lhomme/28731

DOI : 10.4000//homme.28731

ISSN : 1953-8103

Éditeur

Éditions de l'EHESS

Édition imprimée

Date de publication : 1 janvier 2009

Pagination : 223-224

ISSN : 0439-4216

\section{Référence électronique}

François Pouillon, « Corinne Cauvin Verner, Au désert », L'Homme [En ligne], 190 | 2009, mis en ligne le 03 janvier 2017, consulté le 24 septembre 2020. URL : http://journals.openedition.org//homme/28731 ; DOI : https://doi.org/10.4000//homme.28731

Ce document a été généré automatiquement le 24 septembre 2020.

(c) École des hautes études en sciences sociales 


\title{
Corinne Cauvin Verner, Au désert
}

\author{
François Pouillon
}

\section{RÉFÉRENCE}

Corinne CAUVIN VeRneR, Au désert. Une anthropologie du tourisme dans le Sud marocain, Préface d'Alban Bensa, Paris, L'Harmattan, 2007, 318 p., bibl., gloss.

1 IL Y A DEUX MANIÈRES de faire de l'anthropologie du tourisme. La première consiste à se transformer soi-même en touriste, et à étudier ce qui se passe, fût-ce de façon distanciée, en se plaçant dans une problématique du regard. Certains travaux récents de Marc Augé en sont une bonne illustration. La seconde consiste à se lancer, de façon plus classique, dans un travail monographique sur un groupe local, de façon à analyser les interférences sociologiques et mentales, les processus réels qui s'engagent, à long terme, à la suite de la généralisation contemporaine du tourisme de masse. Le phénomène n'épargne pas les coins les plus reculés de la planète, champs clos traditionnels des ethnologues qui, pourtant, ont tendance à faire comme si rien ne s'était passé. Le travail de Corinne Cauvin Verner appartient indiscutablement à cette seconde catégorie : son enquête, conduite de 1994 à 2004 au Maroc, dans la région de Zagora, auprès d'un groupe d'anciens caravaniers reconvertis dans le tourisme de randonnée, au-delà d'une contribution à la connaissance d'un canton du Sud-Est marocain et d'une réflexion théorique sur le tourisme comme objet anthropologique, aide à penser l'histoire des sociétés maghrébines et leurs transformations contemporaines, faites aussi de fidélités.

2 La première partie, «Imageries sahariennes ", évite les généralisations amorphes que l'on a coutume de lire sur l'imaginaire du désert. En ancrant solidement la lecture des auteurs du passé dans les expériences et les émotions du présent, Corinne Cauvin Verner parvient à construire une archéologie du phénomène, s'appuyant sur les récurrences que l'on observe dans une littérature consacrée au désert, lieu immobile s'il en est. Cette démarche la conduit à adopter une position assez déstabilisante par rapport à ces corpus : au lieu d'opposer, comme on a l'habitude de le faire, les textes 
héroïques, kitch ou élégants, des aventuriers et des écrivains-voyageurs, aux vulgaires réductions de l'époque du tourisme de masse, Corinne Cauvin Verner les met en relation active. C'est conduire à revoir les oppositions faciles entre ethnologie et tourisme, car la première n'est au fond pas plus diverse, plus inégale que le second.

3 À l'égard de ces êtres avec qui l'on est amené à frayer dans les aéroports, et que l'on rangerait assez volontiers dans la catégorie métaphysique du "gros con", Corinne Cauvin Verner adopte l'attitude méthodologique qui s'impose, et qui consiste à dire tout simplement le divers de toute chose. Sur cet objet non conventionnel pour l'anthropologie qu'est le tourisme, elle applique avec efficacité les méthodes canoniques de la discipline, et le revendique avec force: elle ne fait pas de l'anthropologie du tourisme, mais de l'anthropologie sociale dans une situation touristique. C'est là toute la richesse de son approche, qui en dit beaucoup plus que les enquêtes extensives ou les analyses statistiques produites habituellement sur ce thème. En dépit des constants changements de plans et d'axes qui découlent de sa recherche des "effets de miroirs", son texte présente un caractère élancé et parfaitement homogène. Débarrassé des faux-fuyants de l'écriture académique, il apporte à l'analyse du vécu une densité sensible assez rare.

On est d'abord intrigué par le caractère réduit de l'échantillon, une frérèche autour d'un patriarche. Mais c'est qu'on tient là le paradigme de toute tribu arabe, et on voit vite les liens s'élargir au réseau des adoptés et des dépendants. On voit aussi l'emboîtement du groupe dans la région, l'État et, à travers les « hordes » de touristes envahisseurs microscopiques et pourtant bien actifs -, le monde. C'est un exercice particulièrement difficile que d'appliquer à ces différentes populations la même règle d'empathie et de distance critique. Corinne Cauvin Verner réussit à nous convaincre que la banalité, l'histoire, la manipulation ne sont pas toujours où on les croit. Elle parvient à sauver ses touristes de la caricature, et ses "indigènes " de l'exhibition, gardant de la pudeur même lorsqu'elle évoque les situations jugées localement comme scandaleuses (alcoolisme, débauche, conflits intrafamiliaux).

De ce travail fondamental qui fait place à la durée comme à la complexité - les deux choses sont liées -, il semble que l'on peut tirer deux conclusions. La première, négative, c'est que dans le jeu des imaginaires ici soigneusement reconstitués, il n'y a pas véritablement de communication. Le désert des indigènes est évidemment beaucoup plus divers que celui des touristes. La relation de transparence est illusoire, de même que le rapport au réel puisque, pour le touriste, le "vrai désert ", c'est au fond celui auquel il a rêvé ; quant à l'indigène, observateur attentif de ces fantasmes, il crée, avec les réalités dont il dispose, les leurres qui lui permettent de donner corps à ces rêves.

6 Conclusion positive quand même, optimiste aussi : Corinne Cauvin Verner récuse le catastrophisme généralisé qui marque le discours sur l'acculturation liée au tourisme. Sur ce terrain, les sécheresses, les guerres de frontières, l'émigration de travail ont fait des dégâts autrement irréversibles. Avec cette manne qui arrive sur une terre désolée, c'est au contraire la condition de survie sur place d'une société des marges qui se dessine. Plus rien n'est comme avant, sans doute, mais comme le note le prince Salina, le héros du Guépard de Lampedusa, ne faut-il pas que tout change pour sauvegarder l'essentiel?

7 Par là, le livre de Corinne Cauvin Verner nous engage à une réflexion plus large sur la société bédouine du Sud marocain. Si l'on suit bien son analyse des recompositions 
d'identité dans l'histoire des contacts avec l'extérieur - là où, de fait, l'identité se construit -, il n'y a que facticité. La fameuse authenticité de la tradition, celle que le tourisme invoque ou interpelle, n'est que fabrication. En revanche, on trouve dans ce qu'elle appelle les stratégies déviationnistes des choses autrement essentielles. Car ce qu'elle réaffirme, c'est que la société bédouine n'est pas une société de la règle, de la conformité : c'est une société du défi, de la transgression, de l'esbroufe. «Déculturés ", ces jeunes gens? L'alcoolisme, la conquête sexuelle, l'affairisme même, c'est la continuation de la fantasia par d'autres moyens. Cet ouvrage est bien un travail d'anthropologie, et un travail important.

\section{AUTEURS}

\section{FRANÇOIS POUILLON}

EHESS, Centre d'histoire sociale de l'islam méditerranéen, Paris.

pouillon@ehess.fr 